\title{
Verification of JUPITER Standard Analysis Method for Upgrading Joyo MK-III Core Design and Management*
}

\author{
Shigetaka MAEDA**, Chikara ITO**, Takashi SEKINE** \\ and Takafumi AOYAMA** \\ **Japan Atomic Energy Agency, \\ 4002 Narita, Oarai, Ibaraki, JAPAN \\ E-mail: maeda.shigetaka@jaea.go.jp
}

\begin{abstract}
In the experimental fast reactor Joyo, loading of irradiation test rigs causes a decrease in excess reactivity because the rigs contain less fissile materials than the driver fuel. In order to carry out duty operation cycles using as many irradiation rigs as possible, it is necessary to upgrade the core performance to increase its excess reactivity and irradiation capacity. Core modification plans have been considered, such as the installation of advanced radial reflectors and reduction of the number of control rods. To implement such core modifications, it is first necessary to improve the prediction accuracy in core design and to optimize safety margins. In the present study, verification of the JUPITER fast reactor standard analysis method was conducted through a comparison between the calculated and the measured Joyo MK-III core characteristics, and it was concluded that the accuracy for a small sodium-cooled fast reactor with a hard neutron spectrum was within $5 \%$ of unity. It was shown that, the performance of the irradiation bed core could be upgraded by the improvement of the prediction accuracy of the core characteristics and optimization of safety margins.
\end{abstract}

Key words: JUPITER Fast Reactor Standard Analysis Method, Core Design, Joyo, Verification, Core Physics Test

\section{Introduction}

One purpose of the experimental fast reactor Joyo of the Japan Atomic Energy Agency (JAEA) is to develop fast breeder reactors by demonstrating the fast reactor safety and operational reliability. Another purpose is to conduct irradiation tests of advanced fuels and materials to be used in the prototype fast breeder reactor Monju and the Japanese Sodium Fast Reactor (JSFR) ${ }^{(1)}$, as well as in fusion and new-concept reactors that require high-dose fast neutron irradiation, in order to demonstrate their performance and integrity under both normal and transient conditions.

However, simultaneous loading of many irradiation test rigs causes a decrease in the reactivity because the rigs contain less fissile materials than the driver fuel. In order to carry out duty operation with as many irradiation rigs as possible, it is necessary to upgrade the core to increase its excess reactivity and irradiation capacity.

Core modification plans have been therefore considered to allow improvement of the irradiation efficiency ${ }^{(2)}$. The proposed modifications include 1) introducing radial reflectors

*Received 7 Feb., 2012 (No. 12-0097) [DOI: 10.1299/jpes.6.184]

Copyright () 2012 by JSME 
of which neutron economy is advanced to improve the neutron economy and 2) reduction of the number of control rods (CRs).

In order to perform the design works for these upgrades, the accuracy of the JUPITER fast reactor standard analysis method ${ }^{(3)}$ developed by JAEA was first verified for small sodium-cooled fast reactor.

\section{Description of Joyo}

Joyo is a sodium-cooled, plutonium-uranium mixed oxide (MOX) fast reactor. The main reactor parameters for the present MK-III core ${ }^{(4)}$ are shown in Table 1. Figure 1 shows an example of the core configuration during an operational duty cycle. The fuel region is divided into two radial enrichment zones to flatten the power.

The MK-III driver fuel is MOX with about $18 \mathrm{wt} \%$ enriched $\mathrm{U}$. The fissile Pu content $\left({ }^{239} \mathrm{Pu}+{ }^{241} \mathrm{Pu}\right) /(\mathrm{U}+\mathrm{Pu})$ is about $16 \mathrm{wt} \%$ in the inner core fuel and about $21 \mathrm{wt} \%$ in the outer core fuel. The active core is approximately $80 \mathrm{~cm}$ in equivalent diameter and $50 \mathrm{~cm}$ in height. There is an approximately $25-\mathrm{cm}$-thick radial reflector region of stainless steel surrounding the core. Shielding subassemblies that contain $\mathrm{B}_{4} \mathrm{C}$ are loaded in the periphery of the reactor grid. Six CRs containing $\mathrm{B}_{4} \mathrm{C}$, of which the ${ }^{10} \mathrm{~B}$ enrichment is $90 \mathrm{wt} \%$, are arranged in the fuel region.

Joyo has two primary sodium loops, two secondary loops, and an auxiliary system as shown in Fig. 2. The sodium coolant enters the reactor vessel at $350{ }^{\circ} \mathrm{C}$ at a flow rate of approximately $1,350 \mathrm{t} / \mathrm{h} /$ loop, and exits the reactor vessel at $500{ }^{\circ} \mathrm{C}$. The maximum coolant temperature at the driver fuel subassembly outlet is approximately $570{ }^{\circ} \mathrm{C}$. An intermediate heat exchanger (IHX) separates radioactive sodium in the primary system from non-radioactive sodium in the secondary system. The secondary sodium loop transports the reactor heat from the IHX to an air-cooled dump heat exchanger (DHX).

Table 1 Main core and plant parameters for Joyo MK-III

\begin{tabular}{lcc}
\hline \multicolumn{1}{c}{ Item } & & Specification \\
\hline Reactor thermal power & $(\mathrm{MWt})$ & 140 \\
Max. no. of irradiation S/A & & 21 \\
Equivalent core diameter & $(\mathrm{cm})$ & 80 \\
Core height & $(\mathrm{cm})$ & 50 \\
${ }^{235} \mathrm{U}$ enrichment & $(\mathrm{wt} \%)$ & 18 \\
Pu content & $(\mathrm{wt} \%)$ & $\leq 30$ \\
Fissile Pu content (inner/outer) & $\left(\mathrm{wt}^{\circ} \%\right)$ & $\sim 16 / 21$ \\
Total neutron flux & $\left(\mathrm{n} / \mathrm{cm}^{2} \cdot \mathrm{s}\right)$ & $5.7 \times 10^{15}$ \\
Fast neutron flux & $\left(\mathrm{n} / \mathrm{cm}^{2} \cdot \mathrm{s}\right)$ & $4.0 \times 10^{15}$ \\
Reflector/shielding material & & $\mathrm{SS} / \mathrm{B}_{4} \mathrm{C}$ \\
Primary coolant temperature (inlet/outlet) & $\left({ }^{\circ} \mathrm{C}\right)$ & $350 / 500$ \\
Operation period per cycle & $(\mathrm{day})$ & 60 \\
Max. excess reactivity $\left(\right.$ at $\left.100^{\circ} \mathrm{C}\right)$ & $\% \Delta \mathrm{k} / \mathrm{kk}$, & 4.5 \\
Control rod worth (total) & $\% \Delta \mathrm{k} / \mathrm{kk}$ & $\geq 7.6$ \\
\hline
\end{tabular}




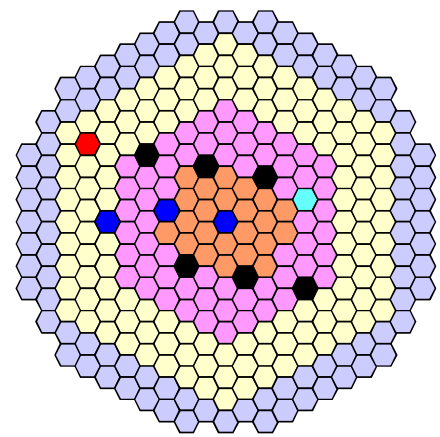

Inner fuel
Outer fuel
Reflector
Control rod
Neutron source
MA-MOX test subassembly
$\square$
Fuel irradiation
Material irradiation
Shielding

Fig. 1 Example of Joyo core configuration

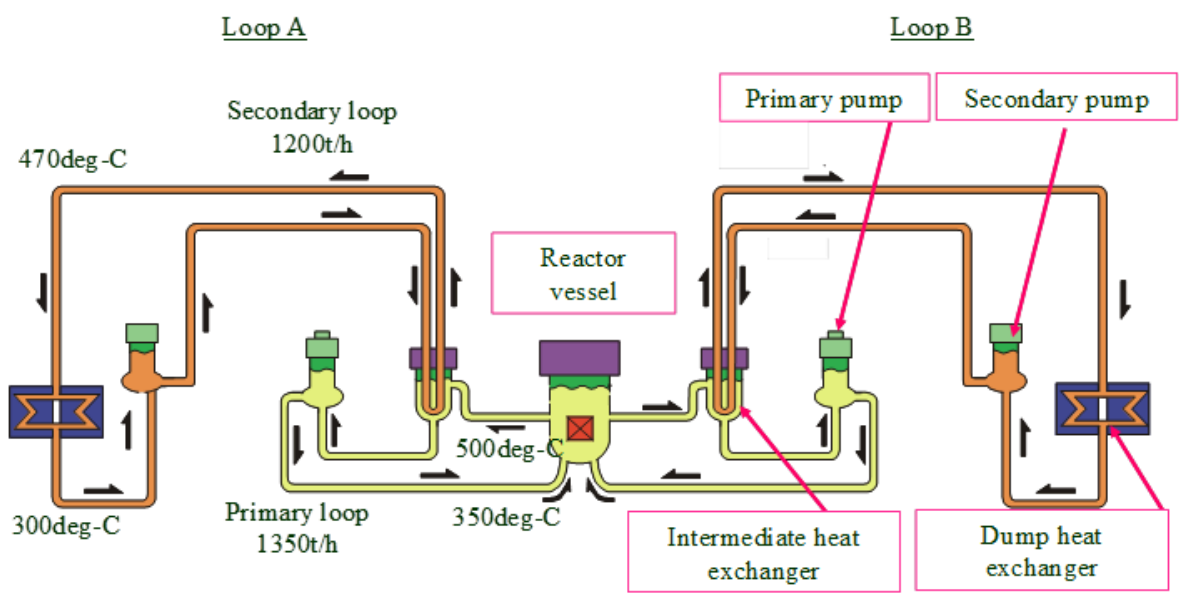

Fig. 2 Joyo MK-III heat transport system

\section{JUPITER Standard Analysis Method}

\subsection{Effective Cross Section Code}

The cell-averaged effective cross sections were calculated by the CASUP one-dimensional calculation code using an ABBN-type 70-group constant set [Japan Atomic Energy Research Institute fast set (JFS)] based on the JENDL-3.2 library ${ }^{(5)}$. The self-shielding factor was calculated using the f-factor table with background cross sections evaluated by Tone's method ${ }^{(6)}$ considering collision probabilities in a heterogeneous cell structure. Current-weighted self-shielding factors were applied to evaluate the transport cross section. To treat the heterogeneity of the core fuel subassemblies and CRs, a one-dimensional heterogeneous ring model was adopted as shown in Fig. 3. The effective homogenized cross section for CRs was calculated by the reaction rate ratio preservation $\operatorname{method~}^{(7)}$.

\subsection{Base Calculation by 3-D Diffusion}

The base core physics calculation was performed using the CITATION-FBR, three-dimensional diffusion code with a triangle geometry, adopting Benoist's anisotropic diffusion coefficients ${ }^{(8)}$ and region-wise fission spectra.

\subsection{Correction for Base Calculation}

A transport and precise mesh correction was applied to the base calculation. The 
correction factors were defined as the difference or the ratio of the nuclear characteristics calculated based on the diffusion and transport theory. In the transport calculation, the discrete ordinates method was used with an $\mathrm{S}_{\mathrm{N}}$ order of 8 . The averaged values of Benoist's diffusion coefficients and corresponding transport cross sections were used in the diffusion and transport calculations. Based on the preliminary calculations, the effects of mesh-size and $\mathrm{S}_{\mathrm{N}}$ order on the transport calculation were assumed to be negligible or to cancel out.

The transport calculation was performed using the TRITAC three-dimensional XYZ transport code ${ }^{(9)}$. A correction factor for sodium void reactivity was evaluated and applied separately for the non-leakage term and the leakage term.

\subsection{Reactivity Coefficient Calculation}

The reactivity coefficients due to the core average temperature and reactor thermal power shift were calculated either by an exact perturbation calculation using the PERKY code or by taking the $\mathrm{k}_{\text {eff }}$ difference for two different temperatures. The Doppler reactivity was obtained by an exact perturbation calculation.

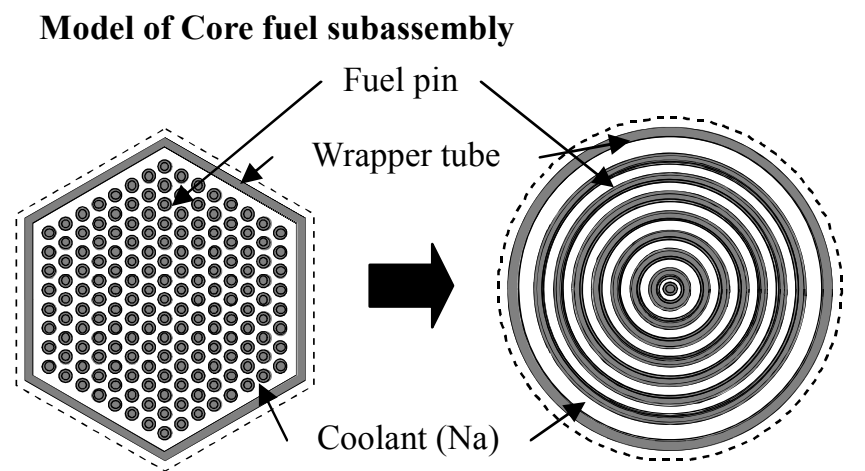

\section{Model of Control rod}

- reaction rate ratio preservation method
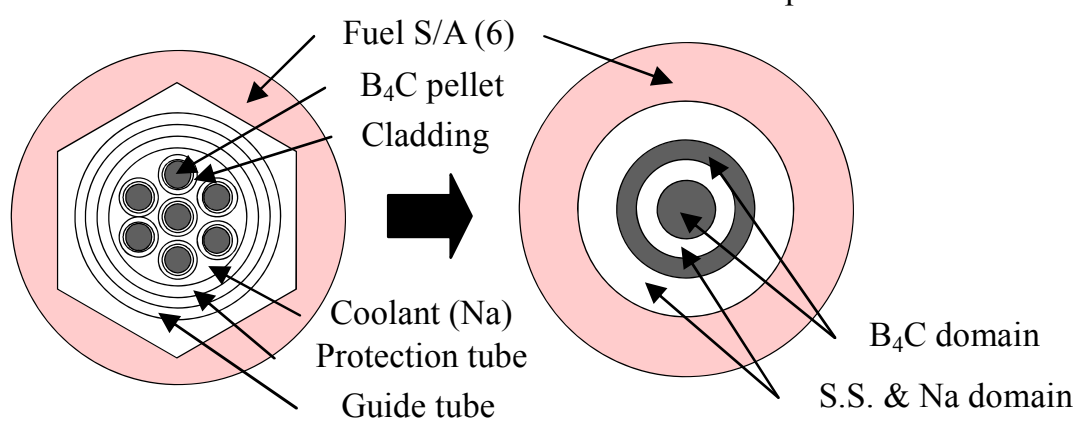

Fig. 3 One-dimensional heterogeneous ring model

\section{Core Physics Test}

\subsection{MK-III Core Performance Test}

The MK-III core performances test began in June 2003. Tests focusing on the neutronics characteristics of the core were conducted during criticality under zero-power, increasing-power, and full rated-power conditions.

The initial MK-III core was not a completely "fresh" core, since $20 \mathrm{MK}-\mathrm{III}$ driver fuel subassemblies had been gradually loaded into MK-II transition cores. By passing through these transition cores, long-term interruption of fuel and material irradiation test programs could be avoided. This also enabled a smooth transition of the core characteristics from the 
MK-II core to the MK-III core. In the initial MK-III core configuration illustrated in Fig. 4, four fuel subassemblies in the center region were replaced by non-fissile material irradiation test subassemblies to offset the excess reactivity caused by 55 fresh driver fuel subassemblies.

Since the initial MK-III core contained 20 already burned driver fuel subassemblies, the accuracy of the core characteristics calculation depends on the accuracy of the fuel composition estimates. The burned fuel compositions for the 20 fuel subassemblies that had been irradiated in the transition core were predicted using the MK-II core management code system MAGI ${ }^{(10),(11)}$. MAGI was developed for predicting core parameters to allow safe operation and to keep refueling plans within the design limitations. The burn-up calculation accuracy has been verified through comparison with fuel burn-up measured by the $\mathrm{Nd}$ method in the MK-II core ${ }^{(12)}$

\subsection{MK-III First and Second Operational Cycle}

After completing the performance tests, the MK-III $1^{\text {st }}$ and $2^{\text {nd }}$ operational duty cycles were carried out in order to characterize the neutron irradiation field and the coolant temperature distribution. The operational period at the rated $140 \mathrm{MWt}$ power was 60 days in the MK-III core. The core configuration during $2^{\text {nd }}$ operational duty cycle is shown in Fig. 5. The fuel composition in each cycle, taking into account the exact critical control bank position, was calculated using the MK-III core management code system HESTIA ${ }^{(11)}$. HESTIA was developed as the standard neutronic calculation code for MK-III core management. It features a finer spatial mesh $(24$ triangles/subassembly and $2.5 \mathrm{~cm}$ axial mesh in the fuel region) and energy mesh (18 groups for neutrons and 7 groups for gamma-rays) to improve neutron and gamma flux calculations. The calculation theory used by HESTIA is the same as that for MAGI and the calculation accuracy for fuel composition is also the same.

In these operational duty cycles, the core burn-up reactivity loss was determined by measuring the excess reactivity change during rated power operation.

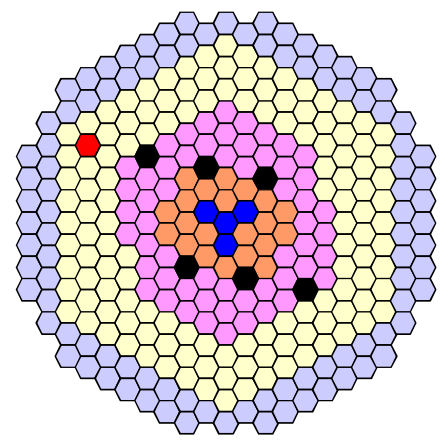

Fig. 4 Core configuration (MK-III performance test)

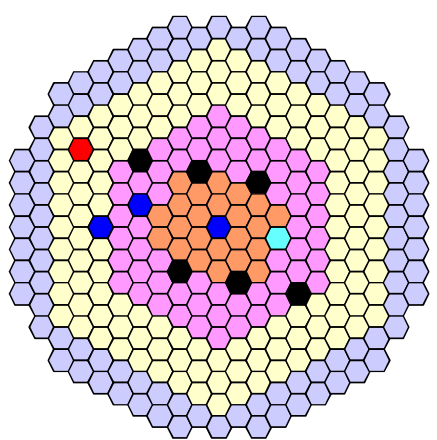

Fig. 5 Core configuration (MK-III $2^{\text {nd }}$ operational duty cycle) 


\section{Verification of Calculation Accuracy}

\subsection{Excess Reactivity}

\subsubsection{Measurements}

Based on the measured critical rod bank position and CR worths, as described in section 5.2, the zero-power excess reactivity in the MK-III performance test core was evaluated to be $2.99 \pm 0.10 \% \Delta \mathrm{k} / \mathrm{kk}$ '. The sodium temperature during the excess reactivity measurement was about $250{ }^{\circ} \mathrm{C}$. The measurement error mainly comes from the uncertainty in $\beta_{\text {eff }}$, which is $0.441 \% \Delta \mathrm{k} / \mathrm{kk}^{\prime}$, and this uncertainty is estimated to be $3 \%\left(0.09 \% \Delta \mathrm{k} / \mathrm{kk}^{\prime}\right)$. The effective delayed neutron fraction $\beta_{\text {eff }}$ was calculated using the diffusion theory code with 18 group cross sections. Nuclear data based on Tuttle ${ }^{(13)}$ for the fission yield, Saphier ${ }^{(14)}$ for the delayed fission spectrum, and Keepin ${ }^{(15)}$ for the delayed neutron family fraction and decay constant were used. The uncertainty in $\beta_{\text {eff }}$ was evaluated to be about $3 \%$ for the MK-I core using the sensitivity coefficients for $\beta_{\text {eff }}$ and the Tuttle evaluation of the uncertainties in the fission yield. Considering the similar core size and fissile content between the MK-I and MK-III cores, the uncertainty in $\beta_{\text {eff }}$ is also assumed to be $3 \%$. This is a part of the experimental uncertainty, and it dominates several neutronics characteristics, such as the CR worth and the excess reactivity.

\subsubsection{Calculations}

In the JUPITER analysis method ${ }^{(3),(16)}$, mesh, transport, heterogeneity and three other corrections were applied to a 6 triangle/ subassembly diffusion theory calculation. The same kinds of biases were then applied as in the previous methods.

\subsubsection{Comparison of Calculation and Measurement Results}

The measured excess reactivity was $2.99 \pm 0.10 \% \Delta \mathrm{k} / \mathrm{kk}$ ' and that calculated by HESTIA was $3.36 \% \Delta \mathrm{k} / \mathrm{kk}^{\prime}$. The difference (C-E) is $0.37 \% \Delta \mathrm{k} / \mathrm{kk}$ ', which was then used to correct the excess reactivity prediction. In the core design process, as the margin for excess reactivity, the sum of the difference (C-E) and the measurement error, which is $0.47 \% \Delta \mathrm{k} / \mathrm{kk}$ ', must be additionally estimated. In the JUPITER standard analysis method, a value of $0.9 \% \Delta \mathrm{k} / \mathrm{kk}$ ' was adopted for the operation margin, which is the same value used in the conventional core design method.

\subsection{Control Rod Reactivity Worth}

\subsubsection{Measurements}

During the MK-III performance test, the CR worth was precisely calibrated using inverse kinetics (IK) method. The reactivity and power traces during several calibration steps are shown in Fig. 6. An example of a differential rod worth profile from the reference calibrations is shown in Fig. 7. It seems that the random error for each calibration step can be significant. However, the effect on the full-travel rod worth is very small. There is a small discrepancy between the measured and calculated axial worth shapes. For the third row rods, such as in this example, the measured worth is higher than the calculated worth at nearly every point.

Experimental and calculated full-travel CR worths from the reference calibrations are compared in Table 2. The rod worth uncertainty, in measurement units of dollars, has an estimated random component of $0.3 \%$ and an estimated systematic component of $1.0 \%$, which add in quadrature to $1.0 \%$. Converting from the calculation units of $\Delta \mathrm{k} / \mathrm{kk}$ ' to dollars, adds a $3 \%$ uncertainty to $\Delta \mathrm{k}_{\text {eff }}$, for a total uncertainty of $3.2 \%$.

Statistical components of experimental uncertainties were evaluated in the following manner. For each measurement step, the factors contributing to the uncertainty in the measured reactivity are considered to be

1) uncertainty in reactivity calculation using the IK method (e1), 
2) uncertainty in zero reactivity value before reactivity insertion (e2),

3) uncertainty in calculation of the shadowing effect removal factor (e3), and

4) uncertainty in determination of the rod position (e4).

The data acquisition system calculates the standard deviation of the reactivity determined by the IK method, and this can then be regarded as e1. The uncertainty e 2 in the zero reactivity is expected to be strongly correlated to e1 because the accuracy in estimating zero reactivity depends on the noise in the count rates of the nuclear instrumentation system (NIS). The stability of the NIS signal was verified by observing the signal trend over time before beginning the $\mathrm{CR}$ calibration, and fluctuations in the mean reactivity were found to be less than $50 \%$ of the signal noise standard deviation. Thus, the uncertainty $\mathrm{e} 2$ in the zero reactivity state was considered to be $50 \%$ of e1. The uncertainty e 3 was evaluated to be $20 \%$ of the absolute deviation of the shadowing effect removal factor from unity, based on differences between measured and calculated shadowing effects at the core center elevation. The measurement error in determining the rod position was estimated to be approximately $0.1 \mathrm{~mm}$ based on the minimum scale division on the CR positioning meter, which was then converted to a percentage uncertainty e4. Since the differential worth curve must be smooth, the above uncertainty estimates could be validated by comparing the measured differential worth (with error bars corresponding to the statistical uncertainties) to the fitted reactivity worth curve. It was found that the measured differential worth agreed with the fitted curve within the estimated statistical uncertainties, thus validating the procedure for uncertainty estimations.

The CR shadowing effect was corrected to the measured values based on the transport theory, 7 group cross sections and an XYZ geometric representation of the core in the TRITAC code (Bando, 1985) considering the actual rod bank positions during the measurement. The bias factors in the middle column are based on the measurements in the last MK-II operational cycle and TRITAC calculations for a third row rod and a fifth row rod. Since the measured worths of the CRs in a given reactor row differ by only a few percent, as seen from the experimental worths in Table 3, the use of a row-dependent bias is justified. The final (biased) calculated worths are low by 3 to $4 \%$ for rods in the third row but only by $1 \%$ for rods in the fifth row.

\subsubsection{Calculation}

The CR worth was calculated using two $\mathrm{k}_{\text {eff }}$ values obtained by the transport calculations with 7 group cross sections in the XYZ geometric model. It was confirmed that the modeling effect of the XYZ core model and the energy group collapsing effect are negligible. S8-P0 with the transport approximation was used. The transport cross section was defined as $1 /(3 \mathrm{D})=\Sigma_{\text {tr }}$ where D represents the Benoist's isotropic diffusion coefficient. These conditions for were commonly used for transport calculations in the present study. The convergence condition for $\mathrm{k}_{\mathrm{eff}}$ was set to be in the range 10-6.

\subsubsection{Comparison of measurement and calculations}

A comparison of the final (biased) calculated values of each $\mathrm{CR}$ worth and the measured value validated the assumption that the calculation error would be less than $5 \%$.

Thus, the calculation accuracy was confirmed to be within $5 \%$, which allowed the design margin to be reduced from 18 to $10 \%$ as shown in Table 3 . This reduction can be largely attributed to the calculation error reduction from 13 to $5 \%$. The reduction in the CR worth due to ${ }^{10} \mathrm{~B}$ burn-up was then re-evaluated using the JUPITER method, and was found to be $5 \%$ when the axial average ${ }^{10} \mathrm{~B}$ burn-up reached 10 at $\%$, which was the design limitation. Based on this evaluation, the correction factor for ${ }^{10} \mathrm{~B}$ reduction due to burn-up was changed from 0.85 to 0.90 to reflect the decrease in the calculation uncertainty, as shown in Table 3. As a result, the correction factor for evaluating the minimum value of the 
CR worth in the design method could be increased from 0.68 to 0.81 .

\subsection{Isothermal Temperature Coefficients}

\subsubsection{Measurements}

The isothermal temperature coefficient was precisely measured in the MK-III core performance test. The isothermal temperature coefficient is an indicator of feedback reactivity that can be measured at low power. To begin this measurement, a uniform temperature of approximately $250{ }^{\circ} \mathrm{C}$ was established throughout the primary system (isothermal), and the excess reactivity was determined at the critical CR bank position. Next, the temperature was slowly raised by approximately $20{ }^{\circ} \mathrm{C}$ by increasing the reactor power from a few $\mathrm{kW}$ to $2 \mathrm{MW}$. The reactor power was subsequently lowered again, and steady conditions were maintained for 30 minutes to allow the primary system temperature distribution to become uniform.

The reactor power was then increased in $20{ }^{\circ} \mathrm{C}$ steps, and the excess reactivity was measured at each step, until the primary system temperature reached approximately $350{ }^{\circ} \mathrm{C}$. Calculated adjustments to account for the change in rod shadowing were made for each excess reactivity determination.

The next day, the reactor temperature was brought back to $250{ }^{\circ} \mathrm{C}$ during an isothermal temperature coefficient measurement with the temperature decreasing in $20^{\circ} \mathrm{C}$ steps. The temperature was decreased by adjusting the dump heat exchanger natural circulation air flow. These ascending and descending measurements were repeated, providing four measurements of the temperature coefficient, the results of which are shown in Fig. 8.

The experimental isothermal temperature coefficient is the slope of a linear fit to a set of measurement data points. The results are shown in Table 4. The data points are highly linear, usually to within $0.1 \%$. Using three of the measurements performed at increasing temperature, the reproducibility error was estimated to be about $1 \%$. The total uncertainty in the coefficient, when expressed in $\Delta \mathrm{k}$ units, is approximately $3.2 \%$.

There is a clear difference of about $4 \%$ between the coefficients measured at increasing and decreasing temperature, which is much larger than the reproducibility error. This difference is considered to be caused by a exclusion of the CR drive shaft expansion to reach full equilibrium before the start of the ascending measurements. An indication of this phenomenon is a $\sim 1 \mathrm{~mm}$ asymptotic change in the critical bank position over about 6 hours during the overnight wait before the descending measurements. Taking this into consideration, the ascending and descending temperature measurements agree well.

\subsubsection{Calculations}

The calculated isothermal temperature coefficient has two main components, Doppler broadening of neutron cross section resonances, and thermal expansion. The values of these components are -0.00053 and $-0.00315 \% \Delta \mathrm{k} / \mathrm{k} /{ }^{\circ} \mathrm{C}$ respectively. An ultra-fine group correction was used in the computation of Doppler broadened cross sections at each temperature. The items contributing to thermal expansion include coolant density change, core radial expansion and fuel axial expansion as shown in Table 5. The JUPITER method described in the excess reactivity section (but with no bias applied) was used to calculate $\mathrm{k}_{\mathrm{eff}}$ at the two temperatures.

\subsubsection{Comparison of measurement and calculations}

The ratio of the calculated and experimental values, C/E, was approximately 0.96 , so that the values agreed within the measurement error. In the core design calculation, the margin for the temperature coefficient was set to $9.2 \%$, which included the $\mathrm{C} / \mathrm{E}$ value of 0.96 and the measurement uncertainty of $5 \%$. In the core design process in the JUPITER standard analysis method, an overall value of $9.2 \%$ was adopted for the margin of the 
temperature coefficient calculation. In the conventional core design method, the margin for each component of the temperature coefficient was set to $30 \%$, except for the core support radial expansion, whose margin was set to $20 \%$, as shown in Table 6 . The same value as that for the conventional design method was adopted for the power coefficient.

\subsection{Burn-up Reactivity Coefficients}

\subsubsection{Measurements}

The CRs are withdrawn three times a day in Joyo to compensate for the decrease in excess reactivity due to core burn-up. The burn-up reactivity coefficients were evaluated from the slope of a plot of the excess reactivity against the integrated reactor power output (average core burn-up). The excess reactivity was obtained using the CR position, CR calibration curve, and the integrated thermal output. Data for initial 8 days were eliminated to avoid the delayed effect of ${ }^{239} \mathrm{Pu}$ production by the decay of ${ }^{237} \mathrm{~Np}$, whose half-life is 2.4 days.

The burn-up reactivity coefficients for the $1^{\text {st }}$ and the $2^{\text {nd }}$ operational cycle were found to be $-4.47 \times 10^{-5} \% \Delta \mathrm{k} / \mathrm{kk}^{\prime} /(\mathrm{MWd} / \mathrm{t})$ as shown in Fig. 9. The measurement error was evaluated to be about 3-4\% in consideration of the statistical error in the CR calibration curve, the error in determining the $\mathrm{CR}$ position and the measurement error in the reactor thermal output.

\subsubsection{Calculations}

The burn-up reactivity coefficients were calculated as a reactivity change per unit thermal output using the JUPITER standard analysis method. The absolute neutron flux was validated by fission rate measurement of ${ }^{235} \mathrm{U}$ dosimeters irradiated in the core during the $1^{\text {st }}$ and $2^{\text {nd }}$ cycle. In this analysis, a burn-up chain involving ${ }^{239} \mathrm{Pu}$ production through ${ }^{237} \mathrm{~Np}$ decay was adopted, which is the same as in the ORIGEN2 code. The excess reactivity calculations in BOC (beginning of cycle) and EOC (end of cycle) were corrected by the transport and mesh correction factors, and the neutron flux was also corrected by the transport method.

\subsubsection{Comparison of measurement and calculations results}

The ratio of the calculated to experimental values, $\mathrm{C} / \mathrm{E}$, was found to be 1.04 . It is considered that the decrease in the atomic number density of major fissile nuclides such as ${ }^{235} \mathrm{U}$ and ${ }^{239} \mathrm{Pu}$ is the factor that dominates the burn-up reactivity coefficients because Joyo has a small core size, which results in a hard neutron spectrum and a small internal conversion ratio ( 0.3 or less). Therefore, the burn-up reactivity coefficients can be predicted accurately even at a high burn-up. The correction factor was set to 1.0 since $\mathrm{C} / \mathrm{E}$ exceeds 1.0. In the core design calculation, the margin for the burn-up reactivity change was set to $5 \%$, which includes the uncertainties in $\beta_{\text {eff }}$ and in determining CR position. A value of $0.5 \% \Delta \mathrm{k} / \mathrm{kk}$ ' was adopted for the burn-up reactivity decrease, which was reduced from $10 \%$ for the conventional core design method to $5 \%$. 
Table 2 Reference control rod calibration results based on inverse kinetics method

\begin{tabular}{cccccc}
\hline Rod No. & $\begin{array}{c}\text { Exp. worth } \\
\left(\% \Delta \mathrm{k} / \mathrm{kk}^{\prime}\right)\end{array}$ & $\begin{array}{c}\text { Base calc. } \\
(\% \Delta \mathrm{k} / \mathrm{kk})\end{array}$ & Bias factor $^{*}$ & $\begin{array}{c}\text { Biased calc. } \\
(\% \Delta \mathrm{k} / \mathrm{kk})\end{array}$ & $\mathrm{C} / \mathrm{E}$ \\
\hline 1 & $2.09 \pm 0.07$ & 2.07 & 0.97 & 2.01 & 0.96 \\
2 & $0.80 \pm 0.03$ & 0.83 & 0.95 & 0.79 & 0.99 \\
3 & $2.03 \pm 0.07$ & 2.03 & 0.97 & 1.97 & 0.97 \\
4 & $2.08 \pm 0.07$ & 2.07 & 0.97 & 2.01 & 0.97 \\
5 & $0.78 \pm 0.03$ & 0.83 & 0.95 & 0.79 & 1.01 \\
6 & $2.06 \pm 0.07$ & 2.03 & 0.97 & 1.97 & 0.96 \\
\hline
\end{tabular}

* Bias factor is obtained from the ratio of the measured and calculated rod worth in the previous MK-II operational cycle

Table 3 Comparison of design margin in control rod worth calculation

\begin{tabular}{|c|c|c|c|}
\hline \multicolumn{2}{|r|}{ Item } & present & modified \\
\hline \multirow[b]{2}{*}{ Correction for base calculation } & \multirow{2}{*}{$\begin{array}{l}\text { E/C (Experiment / Calculation) } \\
{ }^{10} \mathrm{~B} \text { decrease due to burn-up } \\
\text { (Max. 10atm\% in axial average) }\end{array}$} & 0.97 & 1.00 \\
\hline & & 0.85 & 0.90 \\
\hline \multirow{4}{*}{ Uncertainty in calculation } & $\begin{array}{l}\text { Core size change } \\
\text { Asymmetrical arrangement }\end{array}$ & \multicolumn{2}{|c|}{$\begin{array}{l} \pm 1 \% \\
\pm 2 \%\end{array}$} \\
\hline & \multirow{3}{*}{$\begin{array}{ll}\begin{array}{l}\text { Design } \\
\text { margin }\end{array} & \begin{array}{l}\text { Fabrication } \\
\text { tolerance of } \mathrm{B}_{4} \mathrm{C} \\
\text { Calculation error }\end{array} \\
\end{array}$} & \multicolumn{2}{|c|}{ $\pm 2 \%$} \\
\hline & & $\pm 13 \%$ & $\pm 5 \%$ \\
\hline & & $\pm 18 \%$ & $\pm 10 \%$ \\
\hline
\end{tabular}

Table 4 Isothermal temperature coefficient results

\begin{tabular}{ccccc}
\hline $\begin{array}{c}\text { Measurement } \\
\text { date }\end{array}$ & Temp. direction & $\begin{array}{c}\text { Exp. coef. } \\
\left(\% \Delta \mathrm{k} / \mathrm{kk} /{ }^{\circ} \mathrm{C}\right)\end{array}$ & $\begin{array}{c}\text { Fitting error, } \\
\mathrm{R}^{2}\end{array}$ & $\mathrm{C} / \mathrm{E}$ \\
\hline Aug. 26, 2003 & increasing & -0.00369 & 0.9999 & 0.997 \\
Aug. 28, 2003 & increasing & -0.00375 & 1.0000 & 0.981 \\
Aug. 27, 2003 & decreasing & -0.00386 & 0.9998 & 0.953 \\
Aug. 29, 2003 & decreasing & -0.00385 & 0.9999 & 0.956 \\
\hline
\end{tabular}

Table 5 Components of isothermal temperature coefficient reactivity

\begin{tabular}{lc}
\hline \multicolumn{1}{c}{ Component } & Contribution (\%) \\
\hline Doppler & 15 \\
Coolant expansion & 32 \\
Core support plate expansion & 37 \\
Fuel expansion & 5 \\
Structural expansion & 11 \\
\hline
\end{tabular}


Table 6 Comparison of design margin

\begin{tabular}{llc}
\hline \multicolumn{1}{c}{ Item } & \multicolumn{1}{c}{ Present } & Modified \\
\hline Control rod & \multicolumn{1}{c}{$32 \%$} & $19 \%$ \\
Temperature coefficient & $\begin{array}{l}\text { Expansion of core support plate: } \\
\text { Others: } 30 \%\end{array}$ & $9.2 \%$ \\
& \multicolumn{2}{c}{ Expansion of core support plate: $20 \%$} \\
Power coefficient & \multicolumn{2}{c}{ Others: $30 \%$} \\
Burn-up reactivity & $10 \%$ & $5 \%$ \\
\hline
\end{tabular}

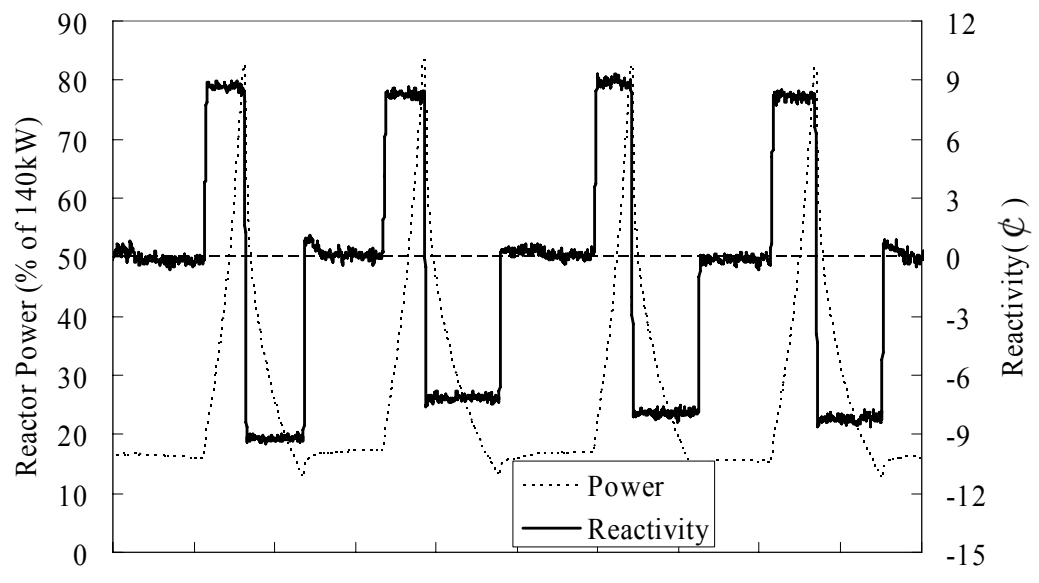

14:00 14:05 14:10 14:15 14:20 14:25 14:30 14:35 14:40 14:45 14:50

Time of Day (July 7, 2003)

Fig. 6 Reactivity and power during part of a reference-control rod calibration

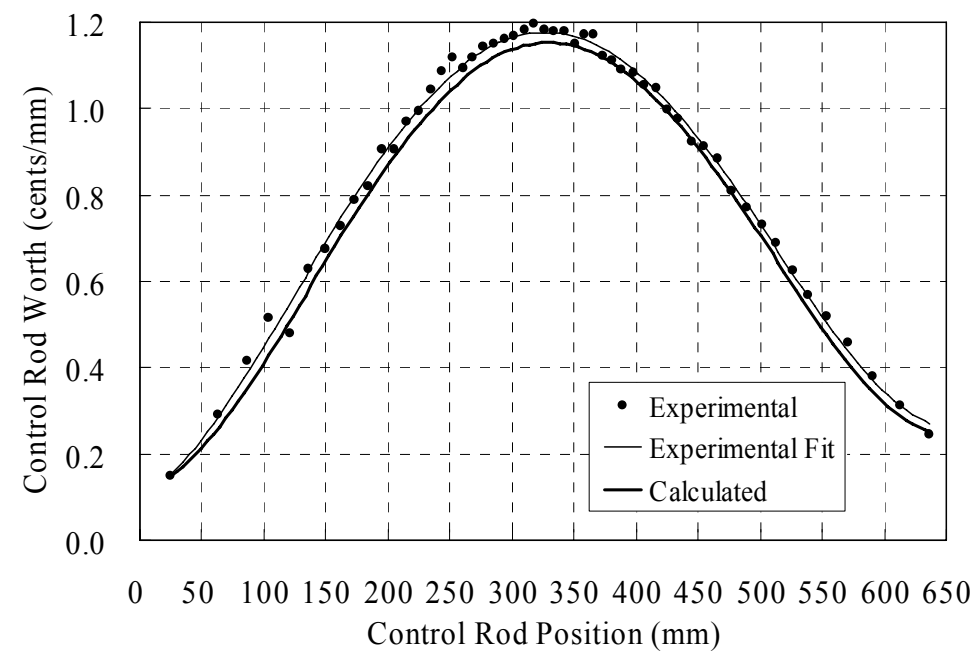

Fig. 7 Comparison of calculated and measured axial profile of control rod worth 


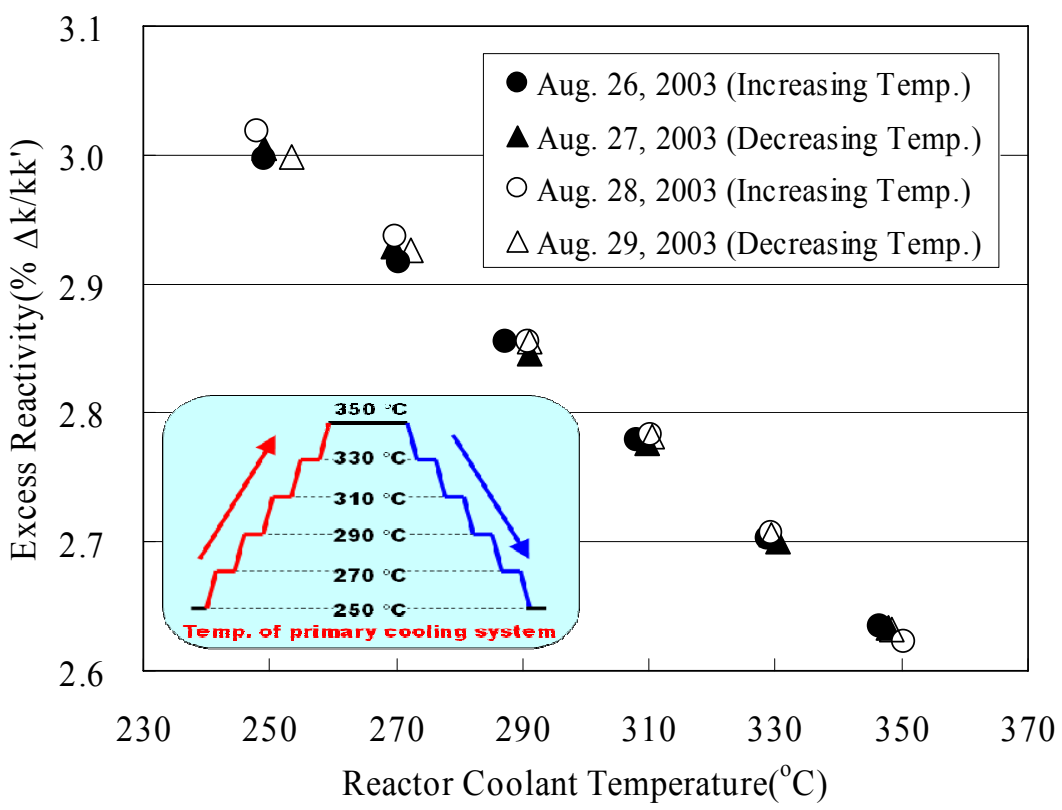

Fig. 8 Isothermal temperature coefficient measurement data

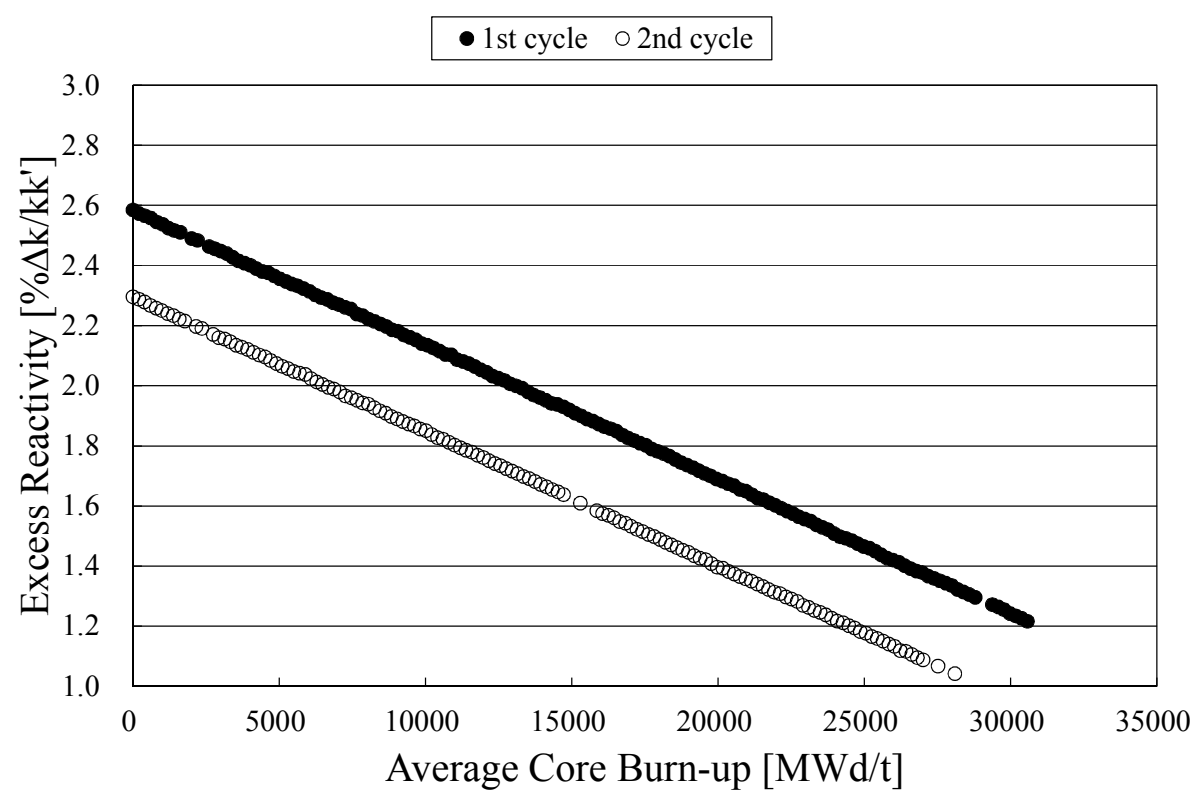

Fig. 9 Burn-up coefficient measurement data

\section{Conclusions}

The JUPITER fast reactor standard analysis method was verified by comparing the calculated and measured characteristics of the Joyo MK-III core. Most of the C/E values were found to be within $5 \%$ of unity. Based on this comparison, the calculation accuracy of the JUPITER standard analysis method for a small sodium-cooled fast reactor with a hard neutron spectrum was clarified. Furthermore, the core design margin for the relevant core characteristics, which is required for upgrading the Joyo core, was determined. Applying the JUPITER method when designing Joyo MK-III core modifications, such as the installation 
of advanced radial reflectors or reduction in the number of control rods, is expected to allow a wide range of irradiation tests to be carried out in this reactor, and to lead the development of innovative FBR plant technology.

\section{References}

(1) M. Ichimiya, T. Mizuno, S. Kotake, "A NEXT GENERATION SODIUM-COOLED FAST REACTOR CONCEPT AND ITS R\&D PROGRAM," Nuclear Engineering and Technology Vol.39, No.3(2007), pp.171-186.

(2) S. Maeda et al., "Characterization of Neutron Fields in the Experimental Fast Reactor Joyo MK-III Core”, Proc. 13th Int. Symp. on Reactor Dosimetry (ISRD13), Akersloot, Netherlands, May 25-30, 2008, 474-482 (2009).

(3) K. Sugino, "JUPITER Experimental Analyses Using a New Constant Set Based on JENDL-3.2," Journal of Nuclear Science and Technologym, Supplement 2, 1002-1005 (2002).

(4) Y. Maeda et al., "Distinguished achievements of a quarter century operation and a promising project named MK-III in JOYO," Nuclear Technology, 150[1], 16-36 (2005).

(5) T. Nakagawa et al., "Japanese evaluated nuclear data library version 3 revision-2: JENDL-3.2," Journal of Nuclear Science and Technology, 32[12], 1259-1271 (1995).

(6) Tone, T., "A Numerical Study of Heterogeneity Effects in Fast Reactor Critical Assemblies,” J. Nucl. Sci. Technol., 12, 8, pp. 467-481. (August 1975)

(7) Kitada, T., et al., "New Control Rod Homogenization Method for Fast Reactors," J. Nucl. Sci. Technol., 31, 7, pp. 647-653 (July 1994).

(8) Benoist, P., "Streaming Effects and Collision Probabilities in Lattices," Nucl. Sci. Eng., 34, p. 285 (1968)

(9) M. Bando et al., "Three-Dimensional Transport Calculation Method for Eigenvalue Problems Using Diffusion Synthetic Acceleration," Journal of Nuclear Science and Technology, Vol. 22, No. 10, pp. 841-850 (1985).

(10) Ohkawachi, Y., et al, "Core management and fast neutron field characterization of JOYO," JAERI-Conf 2006-003, pp. 294-299. (2005)

(11) Aoyama, T., et al., "Characterization of Neutron Field in the Experimental Fast Reactor JOYO for Fuel and Structural material irradiation Test," J. Nucl. Eng. Design, No. 228, pp.21-34. (2004)

(12) Koyoma, S., et al., "Measurement of Burnup in FBR MOX Fuel Irradiated to High Burnup,” J. Nucl. Sci. Technol., Vol. 40, No. 12, p. 998-1013. (2003)

(13) Tuttle, R., "Delayed Neutron Yield in Nuclear Fission, Consultants' Mtg. on Delayed Neutron Properties," IAEA, Vienna, INDC(NDS)-107/G + Special, p. 29. (1979)

(14) Saphier, D., "Evaluated Delayed Neutron Spectra and Their Importance in Reactor Calculation," Nucl. Sci. Eng. 62, p. 660. (1977)

(15) Keepin, G., "Physics of Nuclear Kinetics," Addison-Wesley Publ. Co. Inc., (1965)

(16) Chiba, G.,"A Combined Method to Evaluate the Resonance Self Shielding Effect in Power Fast Reactor Fuel Assembly Calculation,” J. Nucl. Sci. Technol., 40 (7), pp.537-543. (2003) 